\title{
Intraoperative Transesophageal Echocardiography for Congenital Heart Disease
}

\author{
Yi-Chia Wang and Chi-Hsiang Huang \\ National Taiwan University Hospital \\ Taiwan, R.O.C.
}

\section{Introduction}

Transesophageal echocardiography (TEE) has gained its role in perioperative use for congenital heart disease patients, especially with technology improvements in the past decades. It helps with diagnosis confirmation, real-time hemodynamic monitoring, evaluation the successfulness of surgical repair, and surgical planning. The use of intraoperative TEE has major impacts on surgery for congenital heart defects (Randolph et al., 2002). Even with conservative estimates, the financial benefits of TEE in pediatric patients with congenital heart disease are substantial and outweigh its costs (Bettex et al., 2005). In most of the modern cardiac centers, the TEE exam is an essential part of anesthetic management in congenital heart disease surgery.

\section{Indication, contraindication, and complications}

TEE has proven to be an invaluable tool for patients underwent cardiac surgery and cardiac catheterization for congenital heart disease. More than that, TEE is useful for high risk congenital heart disease patients who will have non-cardiac surgeries. It can help with hemodynamic monitoring, and provide real-time detailed anatomic information. In addition, it can help assess ventricular volume and function, intracardiac shunt, valvular disease, right ventricle (RV) or pulmonary artery (PA) systolic pressure, and pericardial effusions. It is reasonable to use intraoperative TEE routinely in congenital heart surgery (Randolph et al., 2002). According to the "practice guidelines for perioperative TEE", TEE should be used in all adult open heart procedures (Thys et al., 2010). The task force of American Society of Echocardiography also described surgery for congenital heart disease is an indication for performance of TEE (Ayres et al., 2005).

Perioperative TEE exam cannot replace the preoperative diagnostic exam. A thorough imaging study must be performed before the operation. Each imaging study has its limitation. TEE performed before surgical incision may disclose a different diagnosis and even result in cancellation of the operation (Huang et al., 2009).

However, there are some situations that TEE is contraindicated. Patients with unrepaired tracheoesophageal fistula, esophageal obstruction or stricture, perforated hollow organ, or 
poor airway control should consider transthoracic echocardiography or epicardial echocardiography instead. Besides, patients with history of esophageal surgery, esophageal varices or diverticulum, gastric or esophageal bleeding, oropharyngeal pathology, severe coagulopathy, cervical spine injury or anomaly require extra attention for TEE probe insertion. Although TEE examination is semi-invasive, some people do suffer from complications related to TEE probe insertion (Huang et al., 2007). These include bradycardia due to vagal stimulation, oropharyngeal injury, and esophageal perforation (Kamra et al., 2011). Besides, airway compromise, vascular compression, and dysphagia may be seen after TEE probe insertion. Physicians should respect individual differences and be vigilant to possible complications.

\section{Specific defects}

\subsection{Atrial septal defect}

Atrial septal defects (ASD) can be classified into four types: ostium secundum, ostium primum, sinus venosus, and coronary sinus defects (Joffe et al., 2008). The pathophysiological effects of ASD are determined by the defect size and degree of left-toright shunting. A large defect or unrepaired defect for a long time may lead to right heart volume overload, and subsequent right atrium (RA), RV, and PA dilation.

Ostium secundum ASD is the most commonly encountered ASD. It is located in the central portion of the interatrial septum. Mitral valve prolapse and regurgitation sometimes accompany this defect. With the advancement in treatment, many people now have transcatheter occluder placement instead of surgical patch repair. Mid-esophageal fourchamber and bicaval views delineate the interatrial septum clearly and are used in the evaluation of ASD repair surgery (Figure 1).

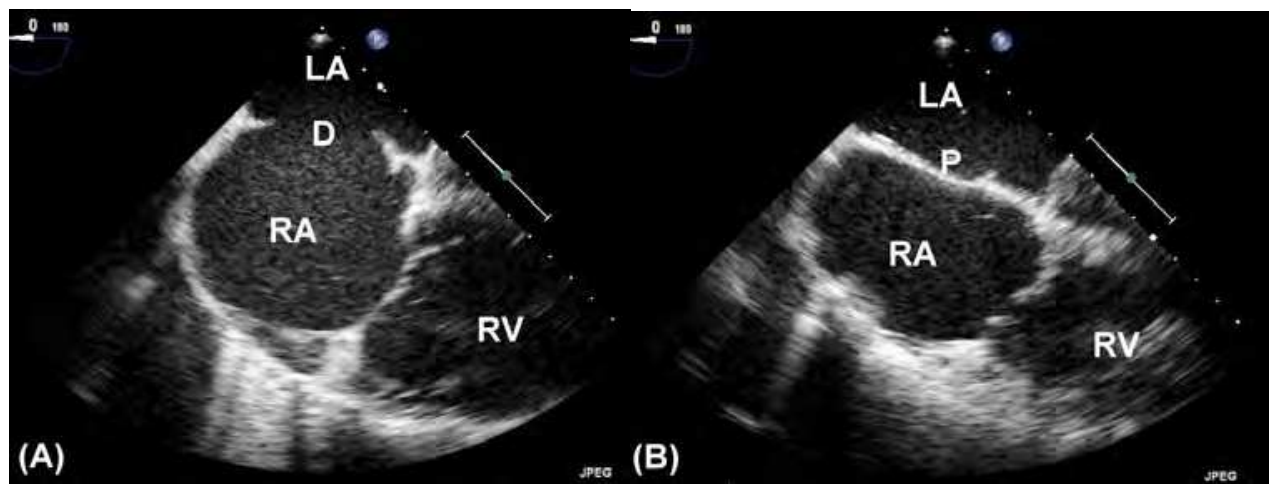

Fig. 1. Secundum atrial septal defect. (A) Preoperative mid-esophageal four-chamber view shows a defect (D) in interatrial septum. (B) The defect is repaired with a patch (P). RA, right atrium; RV, right ventricle; LA, left atrium. 
Ostium primum ASD is also known as partial atrioventricular canal defects (see below). It is located in the inferior portion of the interatrial septum. It can be visualized in midesophageal four- chamber view (Figure 2). Incomplete formation of the septum primum is sometimes associated with anterior mitral leaflet cleft and regurgitation.

Sinus venosus ASD occurs near the superior vena cava (SVC) or inferior vena cava (IVC) entrance. This kind of defect is often associated with partial anomalous pulmonary venous drainage. After surgical repair, we should look not only for the residual shunt, but also the unobstructed flow in SVC, IVC, and pulmonary veins (Figure 3).

Coronary sinus defects are rare, and result from a communication between the left atrium and coronary sinus. They are commonly associated with a persistent left side SVC.

Preoperative TEE exam should confirm the location, size, shunt magnitude and direction, atrioventricular(AV) valve competence, RA and RV size, associated anomalies, and ventricular function. Post-bypass TEE exam should evaluate the adequacy of surgical repair, valvular competence, and ventricular function.

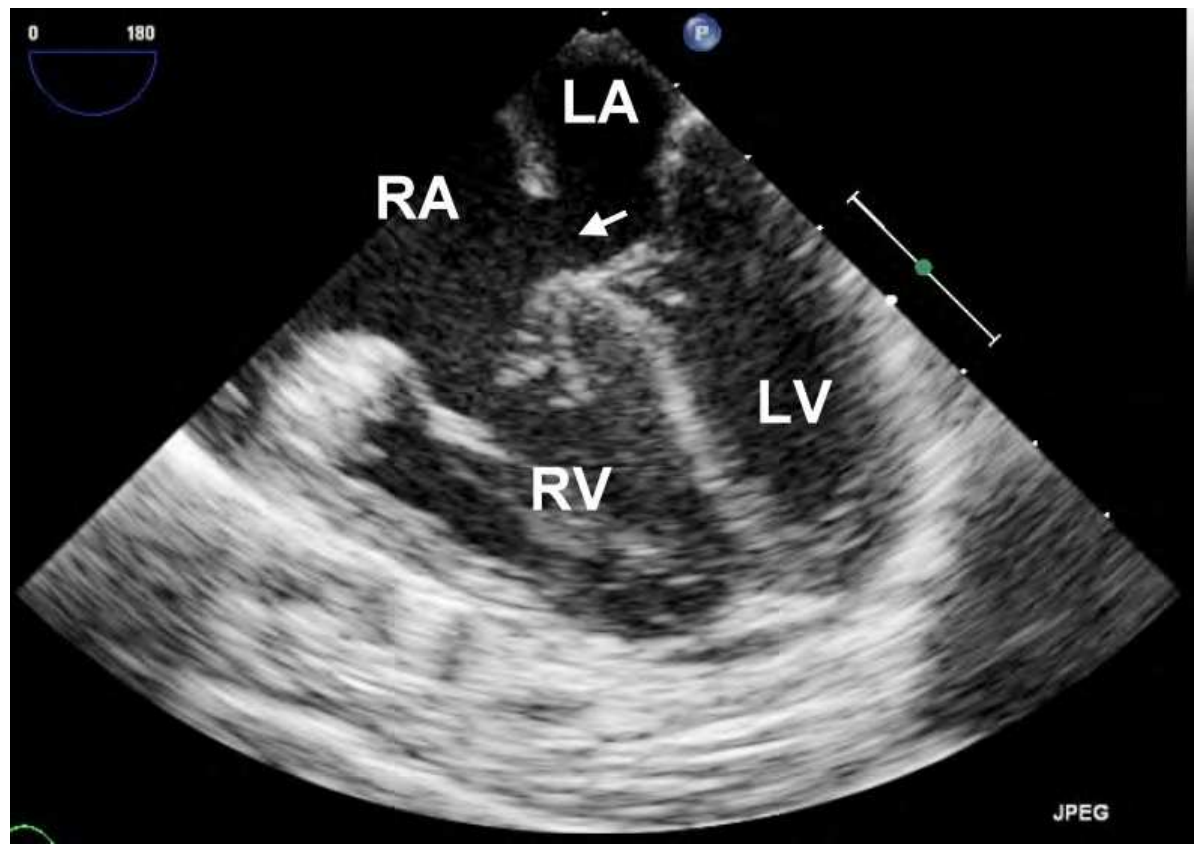

Fig. 2. Mid-esophageal four-chamber view demonstrates a primum atrial septal defect (arrow). RA, right atrium; RV, right ventricle; LA, left atrium; LV, left ventricle. 


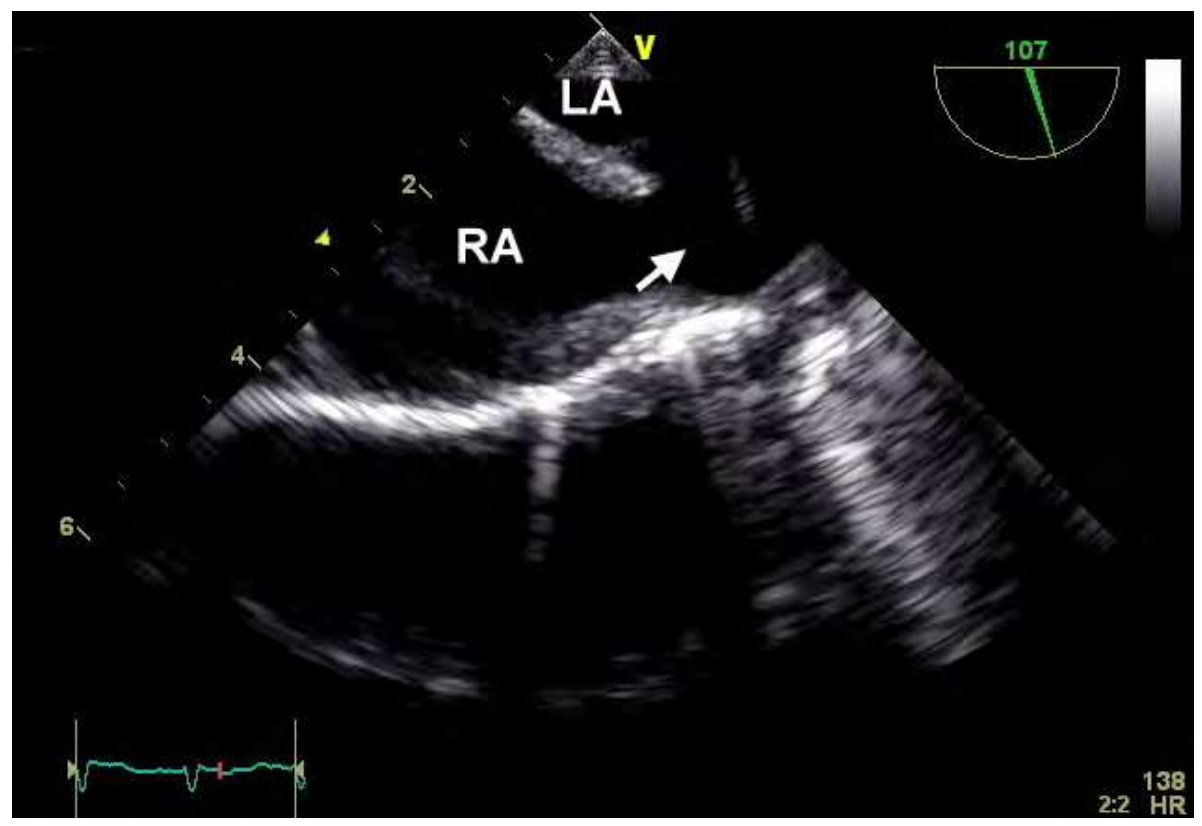

Fig. 3. Modified bicaval view shows a superior sinus venosus atrial septal defect near the superior vena cava and right atrial junction. RA, right atrium; LA, left atrium.

\subsection{Ventricular septal defect}

Ventricular septal defect (VSD) can be classified by its location to four groups: type I, doubly-committed defects; type II, perimembranous defects; type III, atrioventricular defects; and type IV, muscular defects. Perimembranous and muscular defects can be further subdivided to inlet type, trabecular type, and outlet type according to the extension of the defects (Penny \& Vick, 2011). The pathophysiological effects are affected by the size of defect, the systemic and pulmonary vascular resistance, and associated defects such as ASD and patent ductus arteriosus (PDA). The left-to-right shunt can lead to increased left ventricle (LV) volume load, excessive pulmonary blood flow, and decreased systemic cardiac output. A long-standing pulmonary overcirculation may lead to pulmonary hypertension and Eisenmenger's syndrome eventually.

Perimembranous VSDs (Type 2) are confluent with and involve the membranous septum. The defects account for approximately $60-80 \%$ of VSDs. Aneurysmal transformation of tricuspid valve may occur and limit the shunt flow. Tricuspid regurgitation (TR) may occur because the tricuspid valve is deformed. Perimembranous outlet defects can associate with aortic cusp prolapse and even aortic insufficiency. Patients with perimembranous defects may develop RV hypertrophy and right ventricular outflow tract (RVOT) narrowing. When the hypertrophied muscular band divides the RV cavity into two chambers, the condition is called double-chambered RV (DCRV) (Figure 4). The outlet septum may be malaligned anteriorly or posteriorly which can possibly result in RVOT or left ventricular outflow tract (LVOT) obstruction respectively. 


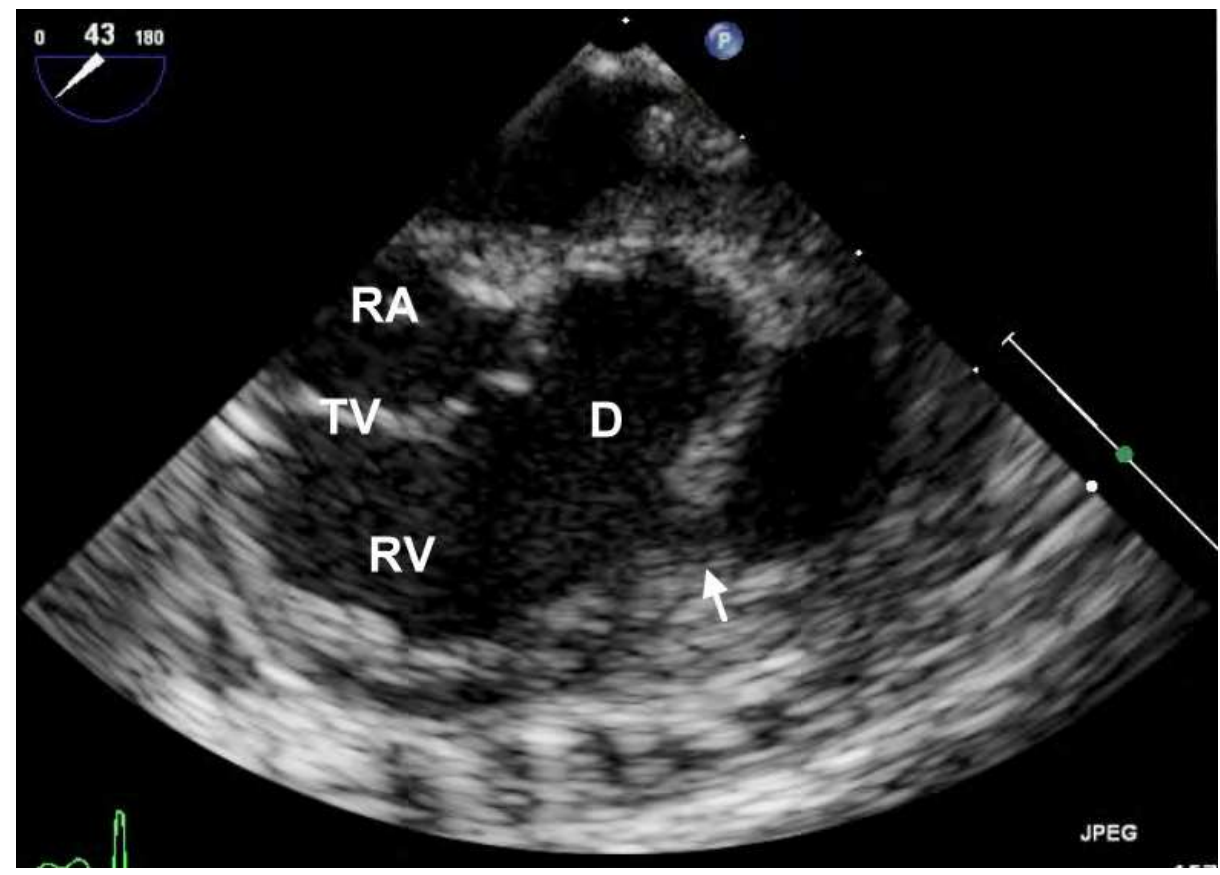

Fig. 4. Perimembranous ventricular septal defect. The right ventricle (RV) inflow-outflow view demonstrates the septal defect (D) and mid-right ventricular obstruction (arrow). RA, right atrium; TV, tricuspid valve.

Doubly committed, subarterial, or supracristal defects (Type I) are roofed by the arterial valves in fibrous continuity. The defects account for approximately $5 \%$ and $30 \%$ of VSDs in western and oriental population, respectively. The defects may associate with aortic valve prolapse and aortic insufficiency (Figure 5).

Muscular defects (Type IV) are completely surrounded by a muscular rim. The defects account for about $5-15 \%$ of VSDs. Multiple muscular defects can occur (Figure 6). The muscular outlet defects can also associate with aortic cusp prolapse and aortic insufficiency.

Atrioventricular canal or inlet defects (Type III) occur close to the atrioventricular valves in the posterior portion of the ventricular septum. The defects account for approximately $5 \%$ of VSDs.

Preoperative TEE exam should confirm the defect location, size, and numbers. Besides, the shunt direction and magnitude, the cardiac chamber size and PA dimension, competence of AV valve, presence of septal malalignment, LVOT or RVOT obstruction, evidence of pulmonary hypertension, and associated cardiac anomalies should be evaluated thoroughly. The velocity of TR jet can be used to calculate PA pressure in the absence of RVOT obstruction. The post-bypass TEE can offer information about the presence of residual shunts or outflow tract obstruction, changes in severity of valvular regurgitation, and ventricular function. 


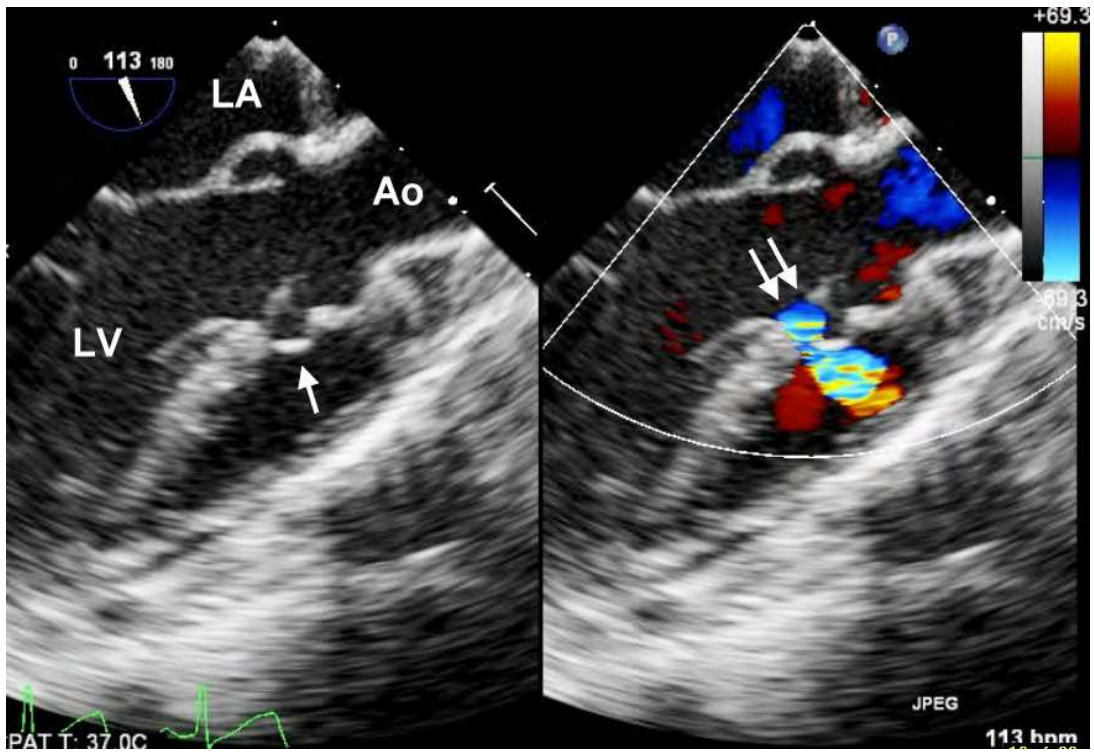

Fig. 5. Doubly-committed ventricular septal defect. Mid-esophageal long-axis view shows the prolapse of aortic cusp (arrow) and the septal defect (double arrow). LA, left atrium; LV, left ventricle; Ao, aorta.

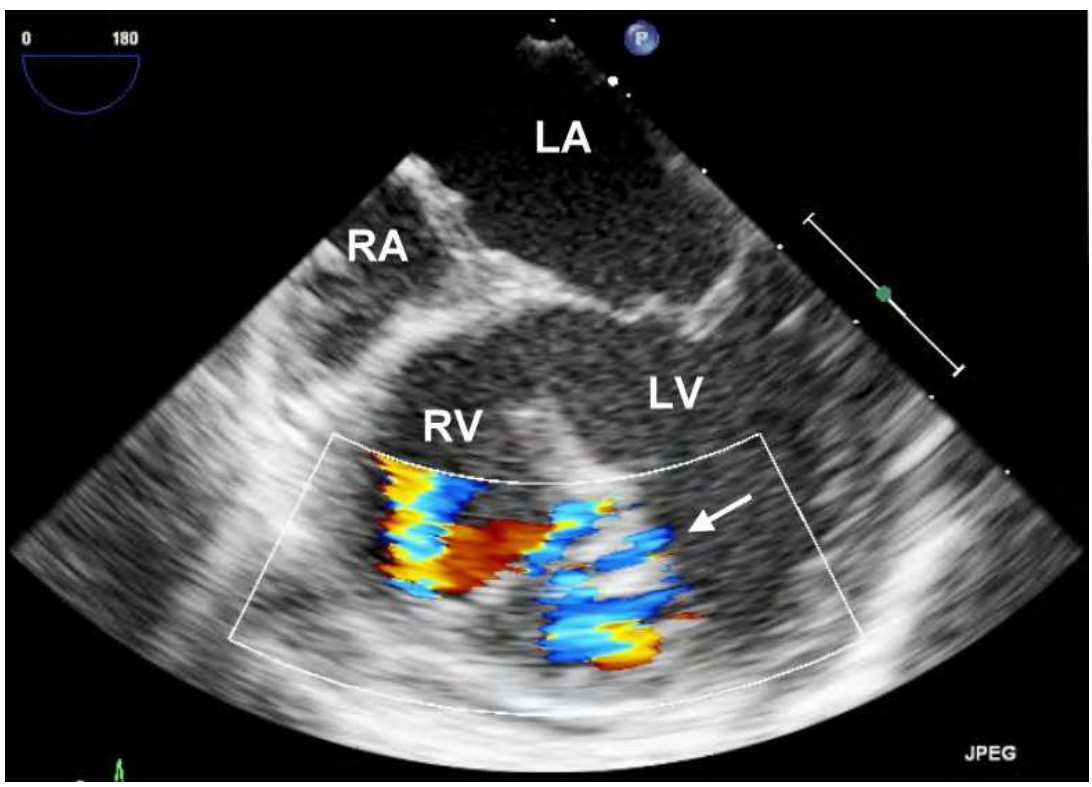

Fig. 6. Mid-esophageal four-chamber view demonstrates multiple muscular ventricular septal defects (arrow). RA, right atrium; RV, right ventricle; LA, left atrium; LV, left ventricle. 


\subsection{Atrioventricular septal defect}

Atrioventricular septal defects (AVSD), also called endocardial cushion defects, are defects involving atrioventricular septum. Normally, mitral valve is attached to a more cephalad position than tricuspid valve. However, in patients with AVSD, their mitral valve and tricuspid valve attach to the same level. There are two types of AVSD, partial AVSD and complete AVSD. In patients with partial AVSD, there is a primum type ASD and anterior mitral leaflet cleft. Though there are usually two orifices for the AV valve, their mitral valve attachment to ventricular septum is not normal, and the leaflet can be thickened, irregular, and dysplasic. Their mitral valve is actually part of the common AV valve and the mitral cleft is a commissure between anterior and posterior bridging leaflets. The attachment of mitral leaflet in the LVOT can cause LVOT obstruction, and poor apposition of the valve can cause mitral regurgitation (MR). Complete AVSD composes single orifice AV valve with deficiency of both atrial and ventricular septum (Figure 7). Rastelli classified this complex into three types according to their different degrees of bridging of superior bridging leaflet, its chordal attachment pattern, and the degree of associative of hypoplasia of the tricuspid anterorsuperior leaflet. The function of common AV valve can be quite variable, ranging from nearly normal function with minimal regurgitation to severely limited dysplastic valve with marked incompetence.

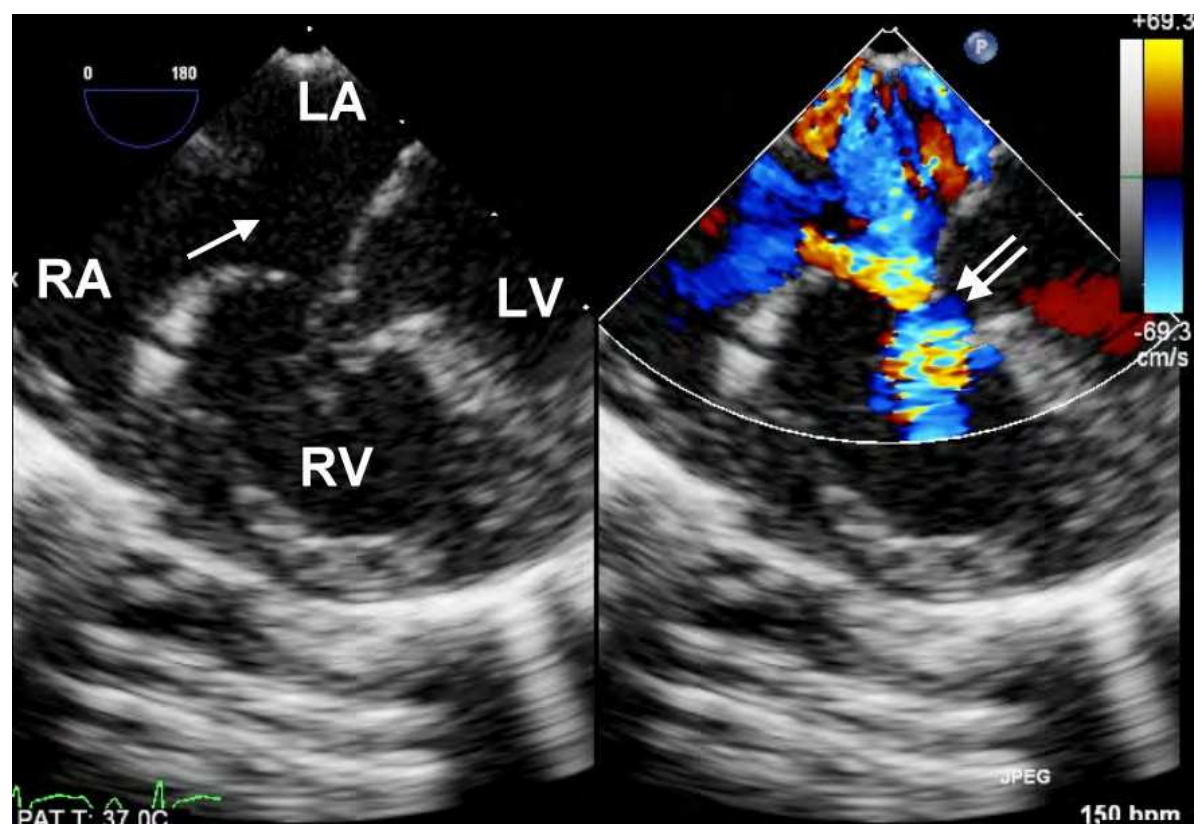

Fig. 7. Complete atrioventricular septal defect. The mid-esophageal four-chamber view shows deficiency of both interatrial (arrow) and interventricular (double arrow) septum.

The pathophysiology of partial AVSD is similar to simple primum ASD. The magnitude of left-to-right shunt is determined by the size of defect and relative ratio of systemic and pulmonary vascular resistance. Mitral cleft can cause significant MR and LV volume 
overload. The MR can pass the primum ASD and results in LV to RA shunt, RA volume overload, and pulmonary overcirculation. In patients with complete AVSD, the presence of concomitant atrial and ventricular shunting can cause increased shunt flow. Pulmonary hypertension, secondary pulmonary vascular change, and increased pulmonary vascular resistance (PVR) can occur thereafter. The hemodynamic changes are affected by the magnitude and direction of shunt flow. There may be different directions of AV valve regurgitation: LV-to-left atrium (LA), RV-to-RA, LV-to RA, or RV-to-LA.

The mid-esophageal four-chamber view of intraoperative TEE can demonstrate the defect of inferior part of atrial septum. Secundum ASD or patent foramen ovale (PFO) can be present in some patients. The broad-base MR jet not originating from the coaptation may suggest the presence of a cleft mitral valve (Figure 8). Cleft mitral valve may be demonstrated in transgastric basal short-axis view. Besides, the presence of ventricular shunting, sizes of both ventricle, ventricular function, magnitude and direction of $\mathrm{AV}$ valve incompetence, degree of AV valve straddling, presence of LVOT obstruction, degree of pulmonary hypertension, and associated cardiac anomalies must be evaluated preoperatively. The postoperative TEE exam should include the evaluation of ventricular function, AV valve competence, and the presence of residual shunt (Cohen et al., 2007). Because valvular regurgitation is quite pressure and load dependent, it is important that we take patient's volume status and cardiac contractility into consideration when comparing preoperative and postoperative regurgitation severity. If prosthetic valve is replaced, it is important to check the function of prosthetic valve and the presence of paravalvular leak.

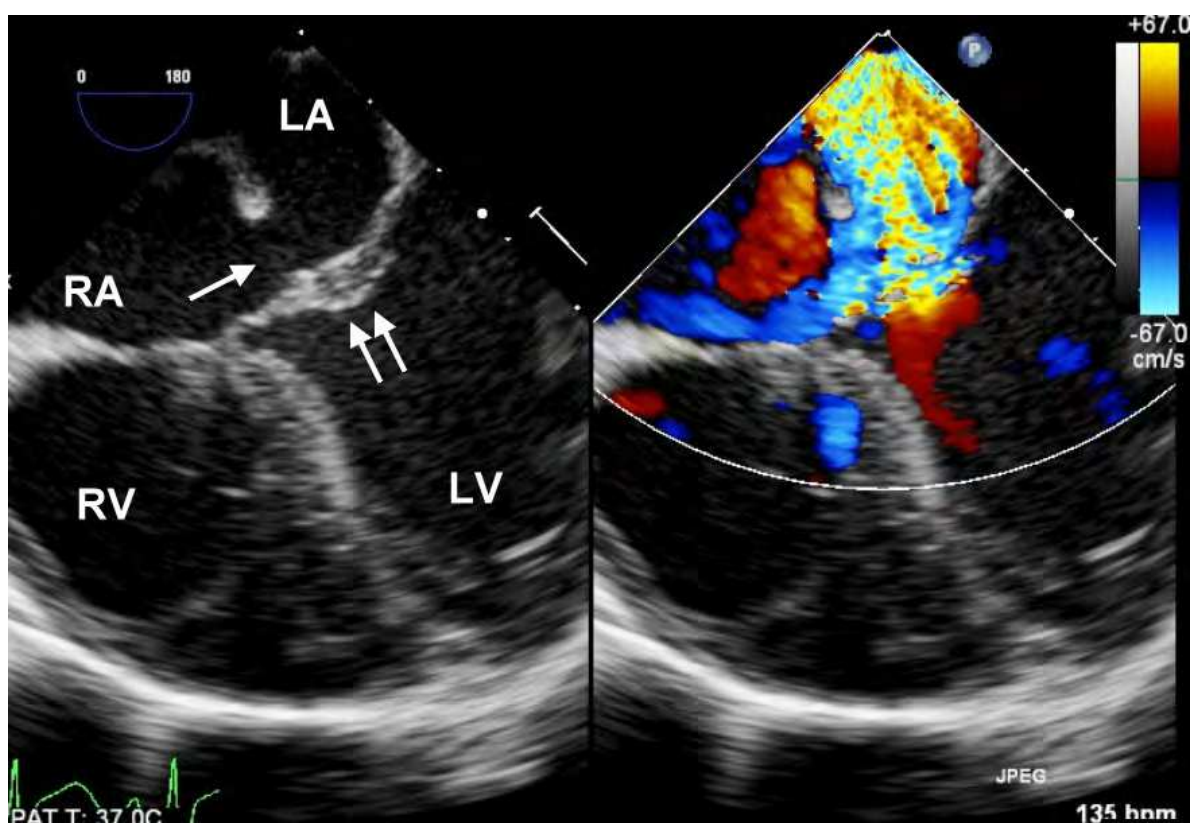

Fig. 8. Partial atrioventricular septal defect. The mid-esophageal four-chamber view demonstrates a primum atrial septal defect (atrial) and mitral cleft (double arrow) with severe mitral regurgitation. 


\subsection{Patent ductus arteriosus and aortopulmonary window}

PDA is a postnatal communication between the main pulmonary trunk and descending thoracic aorta due to persistent patency of fetal ductus arteriosus (Schneider \& Moore, 2006). Shunt flow is determined by diameter of PDA and the pressure gradient. The preoperative TEE can demonstrate the shunt flow in the ascending aorta short-axis view (Figure 9). The size of left-side chambers, ventricular function, valvular regurgitation, degree of pulmonary hypertension, and associated cardiac anomalies must also be evaluated. The postoperative TEE exam can be used to detect the presence of residual ductal flow.

Aortopulmonary defect, also known as aortopulmonary (AP) window, is a defect between ascending aorta and pulmonary artery. Without treatment, pulmonary system will be overloaded due to left to right shunt, and eventually develop pulmonary vascular occlusive disease. A significant portion of the patients have other associated cardiac anomalies. Preoperative TEE can detect a shunt between ascending aorta and PA (Figure 10). Evidence of pulmonary hypertension, ventricular function and size, defect size and shunt pressure gradient can be measured by intraoperative TEE. Surgical treatment usually involves aorta incision, defect visualization, and a patch is sutured to close the defect over the aortic side. The post-repair TEE exam should detect the presence of residual shunt, valvular competence, and ventricular function.

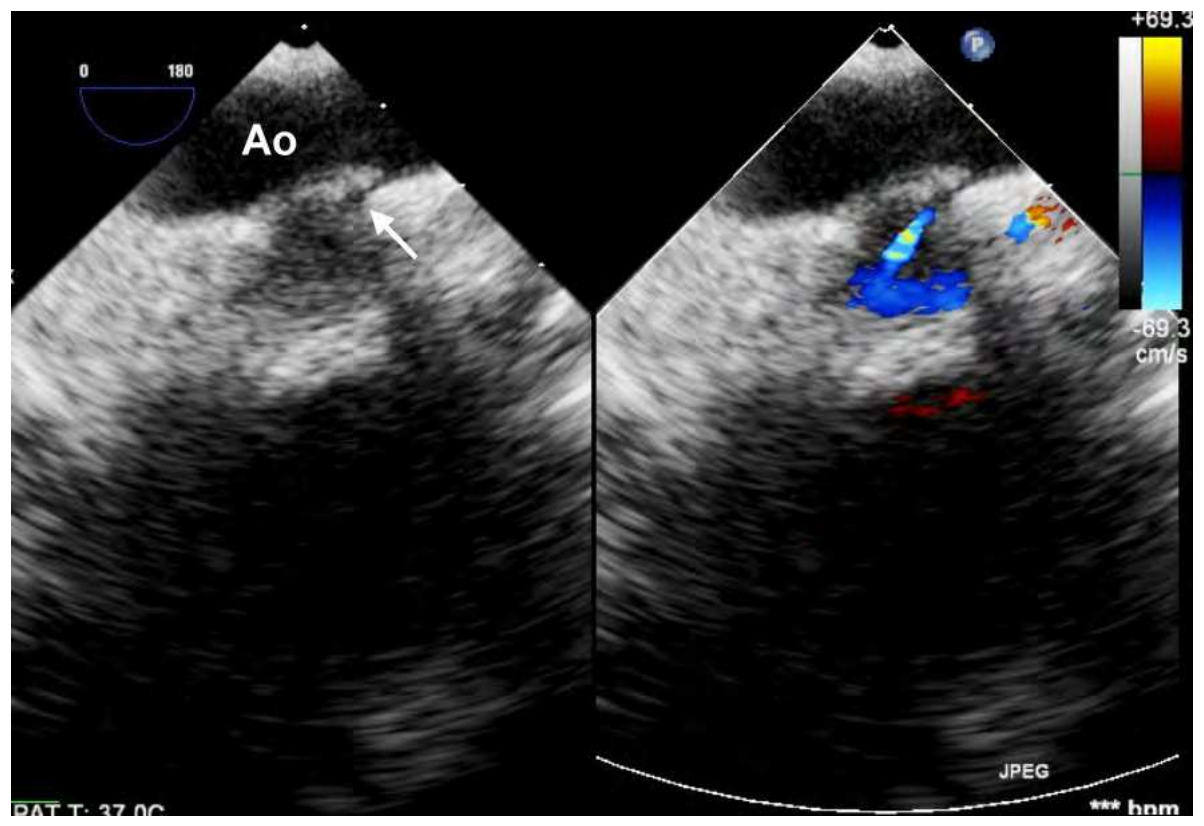

Fig. 9. The upper esophageal aortic arch long-axis view demonstrates the patent ductus arteriosus (arrow) connecting aortic arch and left pulmonary artery. Ao, aorta. 


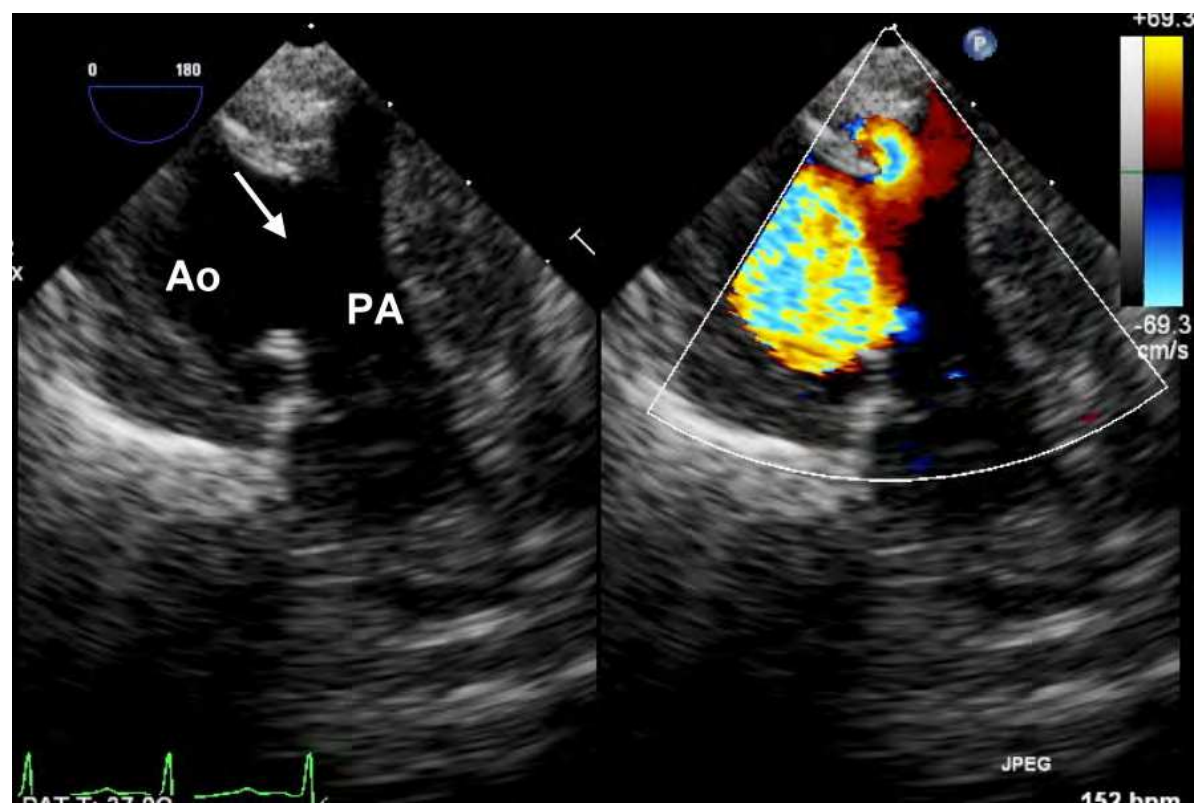

Fig. 10. Aortopulmonary window as a defect (arrow) between ascending aorta and main pulmonary artery. Ao, aorta; PA, pulmonary artery.

\subsection{Truncus arteriosus}

Truncus arteriosus is caused by failure of truncal ridge and aortopulmonary septum to develop, forming aorta and PA. There is a single great vessel arising from a common semilunar valve, and a VSD. The truncal valve can have variable cusps, and valvular incompetence is not uncommon. Further classification is dependent on the existence of truncal septum, and the take-off position of pulmonary arteries. The VSD is caused by failure of conal septum to develop and rotate. It is usually large, non-restrictive, with superior border adjacent to truncal valve. PA is usually of normal size, but stenosis at origin site or diffuse hypoplasia may happen. Other common concurrent cardiac defects include right aortic arch, PDA, persistent left-sided SVC, ASD, and anomalous subclaivan artery.

Surgical repair encompasses separation of branched PA from truncus vessel, establishment of RV-PA continuity by RVOT reconstruction or RV-PA conduit, VSD closure, and repair of associated anomalies. Due to variable coronary anatomy, separation of PA from truncal vessel should be done with care. Mild to moderate truncal valve regurgitation is often tolerated, and will improve over time. However, severe regurgitation is a poor indicator for long term survival. If the truncal valve is severely incompetent, valve replacement should be considered.

Intraoperative TEE should focus on truncal valve morphology and function, anatomy of the main and branched pulmonary arteries, size and position of the intracardiac shunting, AV valve competence, ventricular function and the associated cardiac abnormalities (Figure 11). 
After repair, truncal valve function, residual intracardiac shunt and RVOT patency can be examined with color Doppler. Monitoring of ventricular function is important, because coronary artery may be compromised during pulmonary artery resection, RV-PA conduit reconstruction, and reimplantation of coronary arteries. Pulmonary hypertensive crisis and low cardiac output are potential threats for patients undergoing repair. RV function and severity of TR demonstrated in TEE exam can give anesthesiologist a guide for patient management.

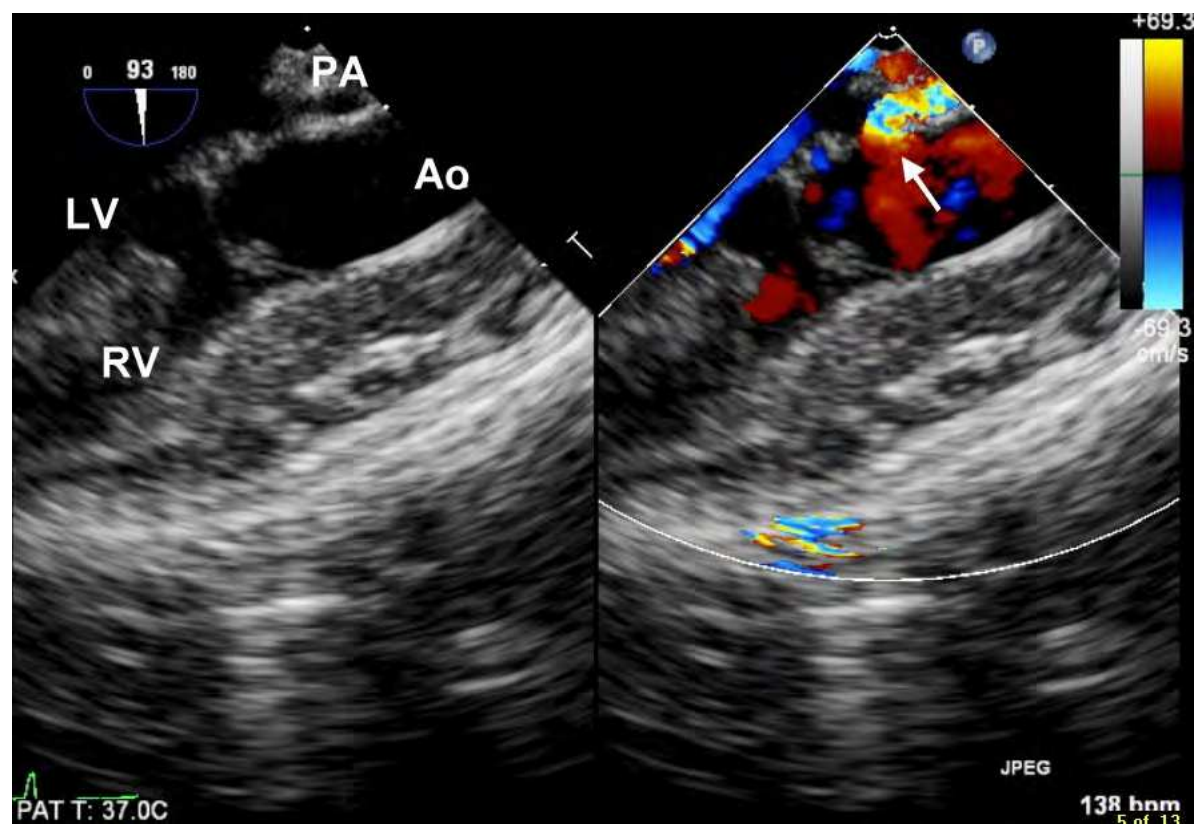

Fig. 11. The mid-esophageal long-axis view shows a truncal vessel overrides the left ventricle (LV) and right ventricle (RV) and gives rise to aorta and pulmonary artery (arrow). Ao, aorta; PA, pulmonary artery.

\subsection{Coarctation of aorta and interrupted aortic arch}

Coarctation of aorta $(\mathrm{CoA})$ is characterized by narrowing of aortic lumen due to thickening or infolding of aortic media (Rosenthal, 2005). Interrupted aortic arch (IAA), on the other hand, is complete discontinuity between two parts of aortic arch. These lesions lie closely to PDA or ligament arterioum. In patients with CoA, the defect can be isolated, or associated with VSD or other complex cardiac disease. The LV afterload is increased in patients with CoA. The site and extent of the stenosis may be seen in upper esophageal level during TEE exam (Figure 12). However, preoperative TEE exam can offer valuable information for other associated anomalies, such as biscupid aortic valve, Shone's complex, and VSD. Surgical treatment includes resection of stenotic area with end-to-end anastomosis, extended resection with primary anastomosis, subclavian flap aortoplasty, and patch augmentation. Some patients have balloon angioplasty and stent insertion in intervention units. Postoperative TEE gives a direct evidence of anatomic site patency and LV function. 


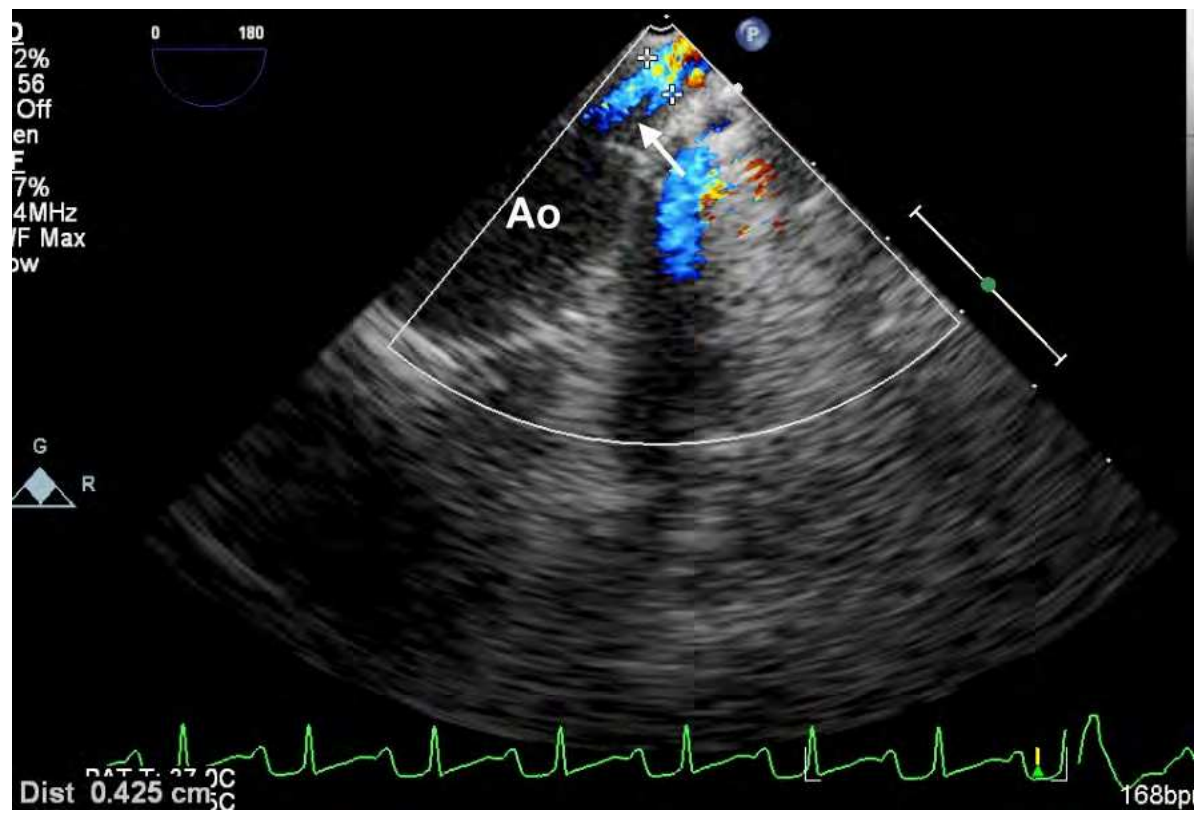

Fig. 12. Upper esophageal aortic arch long-axis view shows coarctation of aorta (arrow). Ao, aorta.

IAA is classified by its interruption location into three types: type A, interruption is distal to left subclavian artery; type B, interruption is between left subclavian artery and left common carotid artery; and type $\mathrm{C}$, interruption is proximal to left carotid artery. The arterial circulation proximal to the interruption is supplied by the LV output. The RV output supplies the arterial circulation distal to the interruption via the ductus arteriosus. Patients usually have PDA, VSD, and aortic valve abnormalities. The VSD is usually conoventricular type with a posterior conal septum malalignment, which causes LVOT obstruction at either subvalvular or valvular level.

Preoperative TEE can be used to evaluate the morphology of aortic arch and PDA. Other coexisting defects should be carefully explored. Size of LVOT and aortic valve should be measured. Failure to detect LVOT obstruction is likely to result in persistent heart failure postoperatively. Surgical treatment for IAA is more complex than simple CoA. Current favorable approach is one-stage repair of interruption, and total correction of intracardiac abnormalities. However, if LVOT obstruction prohibited one-stage correction, modified Norwood operation such as Damus-Kaye-Stansel connection with atrial septectomy may be needed. Postbyapss TEE exam should survey for anastomotic stenosis, aortic or subaortic obstruction, residual atrial or ventricular shunts, and signs of pulmonary hypertension.

\subsection{Anomalous pulmonary venous return}

Partial or total anomalous pulmonary venous return (PAPVR/TAPVR) indicates that some or all of the pulmonary veins enter systemic venous circulation instead of LA. According to 
the connection site of pulmonary veins, anomalous pulmonary venous return (APVR) can be classified as supracardiac type, cardiac type, infracardiac type, and mixed type. In supracardiac type APVR, confluence of pulmonary veins unites to an ascending vertical vein and joins the innominate vein, and then drains into SVC and RA. Sometimes the vertical vein bypasses the innominate vein and joins SVC directly. The connection site between vertical vein and innominate vein or SVC is prone for pulmonary venous obstruction. In patients with cardiac type APVR, the pulmonary vein confluence drains into the coronary sinus, and then to the RA. Some of the patients will have pulmonary veins going directly to RA. In the infracardiac type, the pulmonary vein confluence drains into a descending vertical vein, goes down across diaphragm to portal vein or hepatic vein, and then comes back to RA with IVC.

The pathophysiology is similar to that of ASD in patients with PAPVR. The degree of shunt is determined by the numbers of anomalous pulmonary venous connections. In TAPVR, all of the pulmonary veins drain into RA and there is no pulmonary venous return in LA. Blood in LA is derived from PFO or ASD, which is mixed deoxygenated blood, therefore the patients are cyanotic. In patients with small size or restrictive ASD, the systemic circulation will decrease significantly. In patients with large or nonrestrictive ASD, the magnitude of shunt is determined by the relative ratio of PVR and systemic vascular resistance (SVR).

The pulmonary veins are in the posterior portion of the heart, which makes TEE a valuable tool for optimal imaging and Doppler examination. However, proper probe size should be considered to avoid pulmonary veins compression by probe insertion. PAPVR should be suspected whenever a sinus venous ASD is present. The distinguishable TEE feature of TAPVR includes absence of pulmonary venous connection to LA, identification of alternate pulmonary venous drainage site, and RV overload (Figure 13). The presence of pulmonary venous obstruction, pulmonary hypertension and associated cardiac anomalies must be evaluated. The post-repair TEE exam should check the ventricular and valvular function, signs of pulmonary hypertension, and presence of pulmonary venous obstruction.

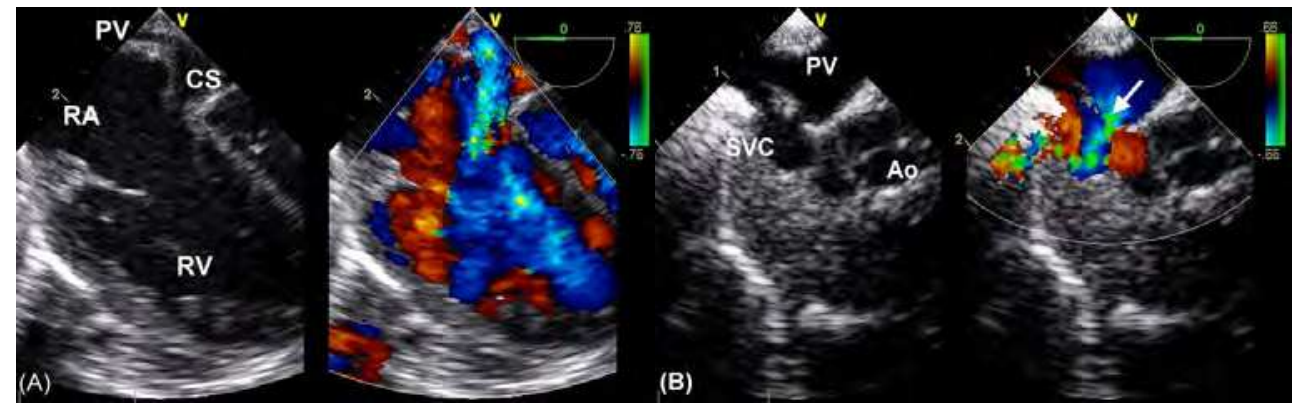

Fig. 13. Anomalous pulmonary venous return. (A) Cardiac type: the modified midesophageal four-chamber view demonstrates the drainage of pulmonary vein (PV) into coronary sinus (CS) and then right atrium (RA). (B) Supracardiac type: the modified midesophageal five-chamber view shows the dainage of PV into superior vena cava (SVC) (arrow). RV, right ventricle; Ao, aorta. 


\subsection{Tetralogy of fallot}

Tetralogy of Fallot (TOF) consists of VSD, overriding aorta, RVOT obstruction, and RV hypertrophy. It can be associated with right aortic arch, additional VSDs, absence of the pulmonic valve, coronary artery anomalies, systemic venous anomalies, AP window, and LVOT obstruction. Surgery involves VSD closure and repair or reconstruction of RVOT (Shinebourne et al., 2006).

The pathophysiological changes in patients with TOF are related to the shunt flow across a large VSD and the degree of RVOT obstruction. RV pressure is increased due to large VSD flow and RVOT obstruction. When the RV pressure is greater than systemic pressure, a right-to-left shunt and arterial desaturation will ensue. There may be little or no right-to-left shunt if the RVOT obstruction is not severe. The common associated cardiac anomalies include right-sided aortic arch in $25 \%$, ASD in $10 \%$, and coronary anomalies in $10 \%$ of patients with TOF.

Preoperative TEE exam can evaluate the degree of RV hypertrophy and aortic overriding, the site and severity of RVOT obstruction, size and location of VSD, direction and magnitude of shunt flow, ventricular and valvular function, morphology of pulmonary arteries, and associated cardiac lesions such as ASD. Overriding aorta and anterior malalignment of outlet septum can be best seen in mid-esophageal aortic valve long-axis view (Figure 14). RVOT obstruction and shunt across VSD can be evaluated in mid-esophageal RV inflow-outflow view (Figure 15). Valvular and supravalvular pulmonary stenosis can be demonstrated in upper-esophageal aortic short-axis view. Post-repair TEE evaluation should include the presence and degree of residual RVOT obstruction, residual intracardiac shunt, peripheral pulmonary stenosis, aortic and pulmonary regurgitation, and ventricular function.

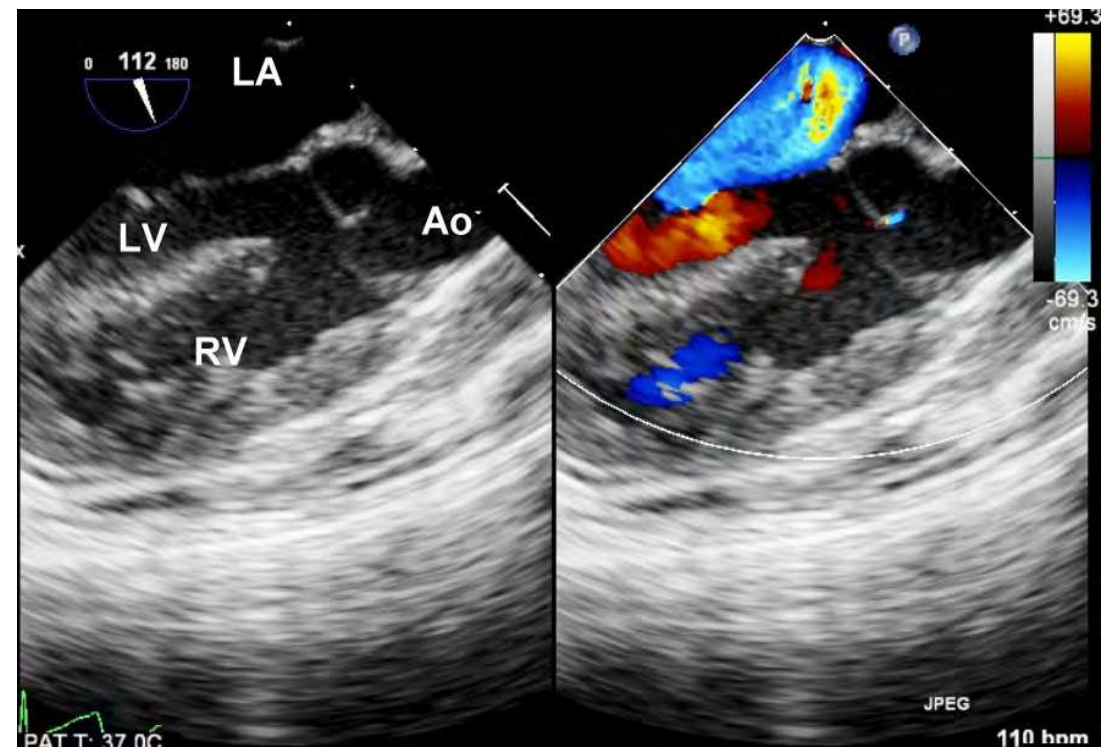

Fig. 14. Tetralogy of Fallot. The mid-esophageal aortic valve long-axis view demonstrates the overriding of aorta. LA, left atrium; LV, left ventricle; RV, right ventricle; Ao, aorta. 


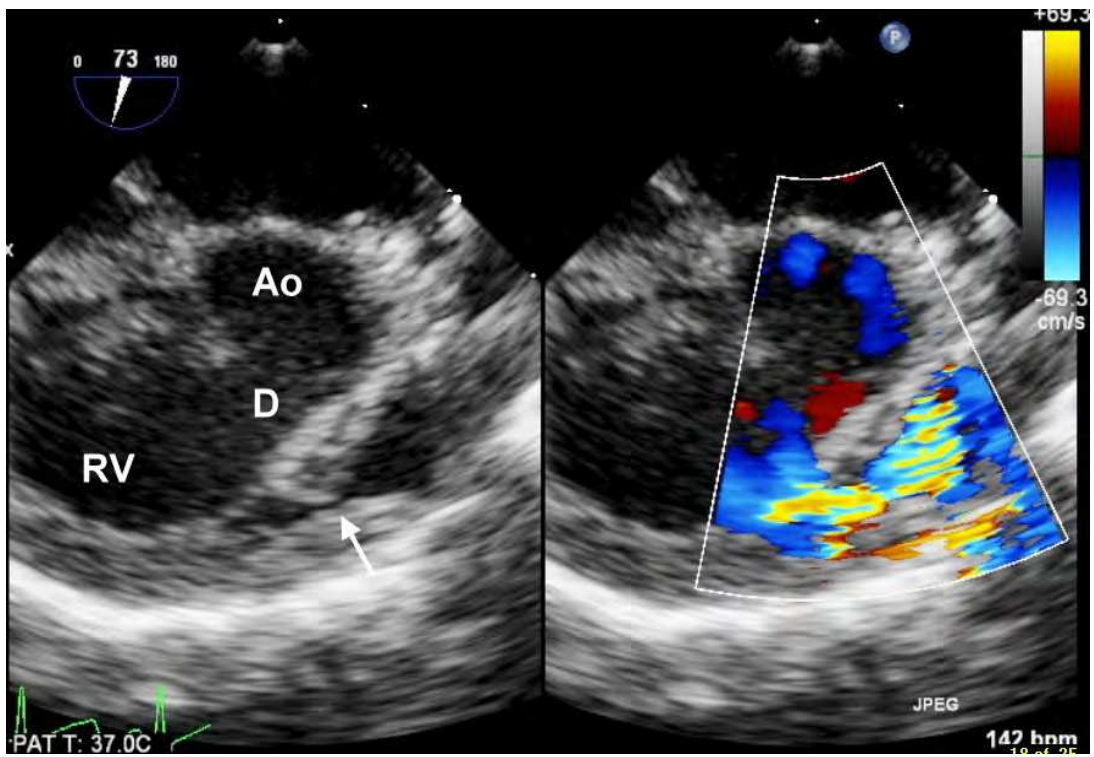

Fig. 15. Tetralogy of Fallot. The right ventricle (RV) inflow-outflow view shows a ventricular septal defect (D) and infundibular pulmonary stenosis (arrow). Ao, aorta.

\subsection{Ebstein's anomaly}

Ebstein's anomaly is characterized by abnormal attachment of septal and posterior tricuspid leaflets in the RV, away from normal tricuspid annulus position. The anterior leaflet is normally attached at annulus, but morphologically enlarged, "sail-like", and tethered to RV wall. The anterior leaflet may functionally obstruct the RVOT. Because tricuspid valve orifice is displaced downward to RV cavity at the junction of the inlet and trabecular components, the proximal portion of the RV is functionally integrated into RA, termed atrialized RV. The severity of hemodynamic compromise is related to the downward displacement of the leaflets, the degree of outflow tract obstruction and valvular regurgitation, the severity of myocardial dysfunction, and other concomitant cardiac abnormalities. RV output is decreased by decreased RV volume and varying degrees of RVOT obstruction. The most commonly accompanied disease is secundum type ASD or PFO. Cyanosis will occur if there is a large right-to-left shunt. Clinical presentation varied extremely from normal tricuspid function found incidentally on autopsy to severe cyanosis, compromised cardiac function, and fetal death. Appropriate surgical intervention depends on the age at presentation and associated anomalies. Tricuspid valve is either repaired or replaced depending on the extent of atrialized ventricle and morphology of tricuspid valve. Single ventricle repair may be performed in patients with poor RV condition.

Considering the variety of the disease entity and different surgical approaches, intraoperative TEE has a significant role in preoperative evaluation and decision making. In mid-esophageal four-chamber view, we can calculate the displacement index, which is the apical displacement of tricuspid valve septal leaflet in millimeters indexed to body surface area. A displacement index more than $8 \mathrm{~mm} / \mathrm{m}^{2}$ is a sensitive predictor of Ebstein's anomaly 
(Oechslin et al. 2000). The preoperative TEE evaluation should include the RA dimension, size and shunt magnitude of ASD, the morphology of tricuspid leaflets, the severity of TR, the presence of RVOT obstruction, ventricular function, and associated cardiac anomalies (Figure 16). Postoperatively, we should evaluate tricuspid valve function, residual intracardiac shunting, residual RVOT obstruction, and RV dysfunction.

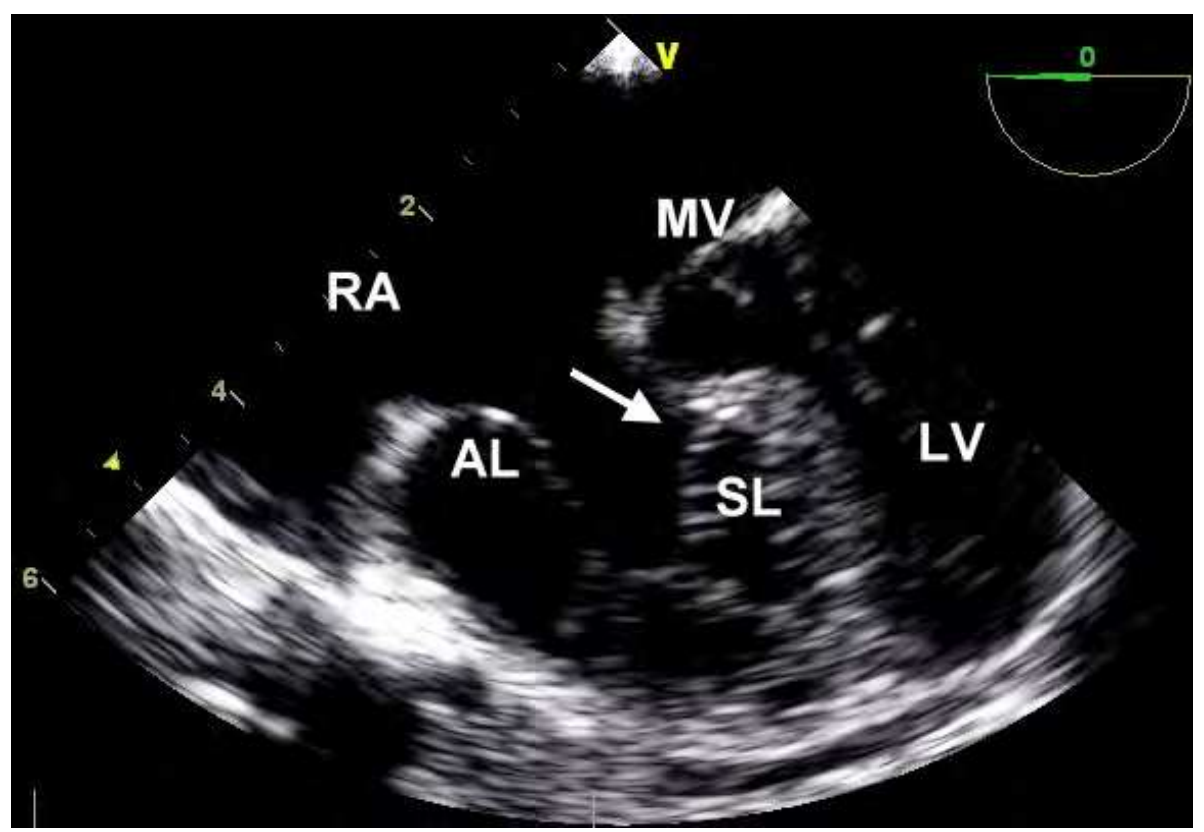

Fig. 16. Ebstein's anomaly. The mid-esophageal four-chamber view demonstrates the "saillike" anterior leaflet (AL) of tricuspid valve and downward attachment (arrow) of septal leaflet (SL) of tricuspid valve. RA, right atrium; $\mathrm{LV}$, left ventricle; $\mathrm{MV}$, mitral valve.

\subsection{Transposition of great arteries / congenitally corrected transposition of great arteries}

Dextro-transposition of great arteries (d-TGA) stands for 5-7\% in congenital heart disease. It is characterized by concordance of the $\mathrm{AV}$ connection and discordance of the ventriculoarterial (VA) connection. Without treatment, 30\% of patients will die in one week, $50 \%$ of patients will die in one month, and $90 \%$ of patients will die in one year. Balloon atrial septostomy and prostaglandin E1 for PDA patency are usually given for flow communication. Preoperative TEE exam should include the assessment of the AV and VA connections, outflow tract obstruction, systemic to pulmonary communications, ventricular size and function, and the associated cardiac pathology (Figure 17).

Surgical treatment for d-TGA has changed significantly through the years. Before mid 1980, the favored approach for infants with d-TGA is atrial switch procedure (Mustard or Senning operation). Surgeons will redirect the blood flow from SVC and IVC through mitral valve, then to LV. The heart will pump the blood from LV to PA. Pulmonary vein flow will be 
directed to RV, aorta, and systemic circulation. This changes the parallel, noncommunicating circulation to serial connection with oxygenation. The intraoperative study mainly involves an assessment of systemic and pulmonary venous pathways. We should look for obstruction of systemic and pulmonary venous return, baffle leak, and ventricular function. Though atrial switch operation corrects hemodynamic abnormalities, it does not correct anatomical imperfections. Later complications include systemic RV failure, baffle obstruction, and arrhythmia.

Arterial switch operation, the Jatene procedure, has been performed for anatomical repair since 1980s (Skinner et al., 2008). The great arteries are transected above the sinus valsalva and anastomosed to their appropriate ventricular outflows. Coronary arteries are translocated to the systemic outflow. Perioperative TEE should evaluate the size and flow of two neo-arteries, and check for any valvular stenosis or regurgitation. Because coronary arteries are relocated, TEE becomes an important tool for segmental and global function evaluation, thus providing indirect evidence of coronary perfusion.

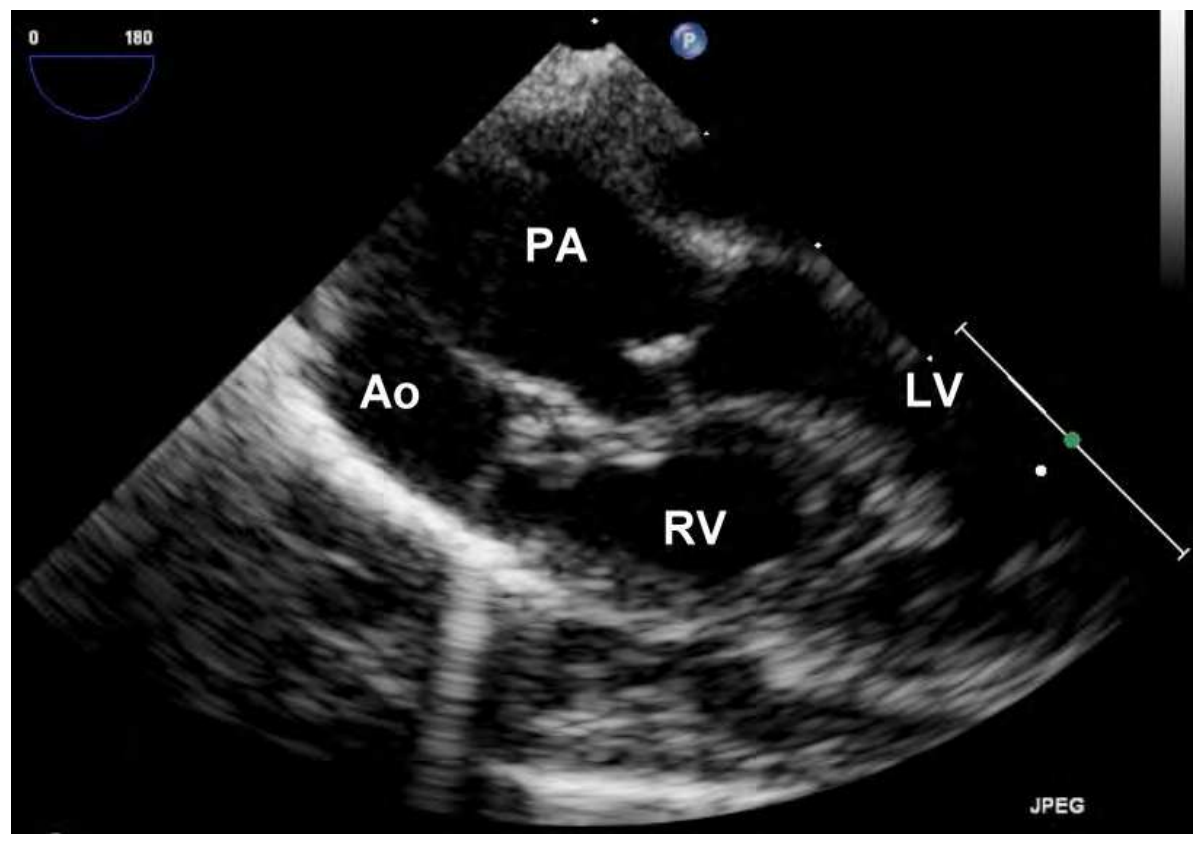

Fig. 17. Transposition of great arteries. The pulmonary artery (PA) arises from left ventricle (LV) and the aorta (Ao) arises from right ventricle (RV).

Levo-transposition of great arteries (l-TGA), also commonly referred to as congenitally corrected transposition of the great arteries (ccTGA), is an acyanotic congenital heart disease. In segmental analysis, this condition is described as AV discordance and VA discordance, with aorta anterior and to the left of the PA. RV serves as the systemic ventricle. Although the physiology of blood flow is correct, systemic RV may develop failure progressively. 
Double switch operation may be performed for patients with 1-TGA. It is a combination of atrial switch operation and arterial switch operation. The preoperative TEE exam should evaluate the relationship of great arteries, presence of outflow tract obstruction, ventricular and valvular function, and associated intracardiac anomalies. The post-repair TEE exam should focus on the systemic and pulmonary venous return pathway, ventricular and valvular function, and anatomy of outflow tract and neo-great arteries.

\subsection{Double outlet right ventricle}

The key feature of double outlet right ventricle (DORV) is the two great arteries arising primarily from RV. For each artery, RV should contribute more than $50 \%$ of it blood flow. There are four types of VSD in DORV patients: subaortic VSD, subpulmonary VSD, doubly committed VSD, and remote VSD. DORV with subaortic VSD is the most common variety in DORV. The conal septum here usually deviates anterior and leftward, and sometimes causes subpulmonary or pulmonary valve stenosis. If there is no pulmonary stenosis, pulmonary blood flow is determined by the relationship of SVR and PVR. If the VSD is subaortic and pulmonary stenosis exists, the presentation is similar to TOF. The degree of cyanosis is dependent on the severity of pulmonary flow obstruction.

DORV with subpulmonary VSD is caused by malalignment of conal septum, which should be differentiated from pure subpulmonary VSD. The conal septum is deviated to posterior and right, sometime causing subaortic narrowing. The Taussig-Bing malformation is a special variant of DORV with subpulmonary VSD, side by side great arteries, aorta at right side, and bilateral subarterial conus. The physiology of this variant is similar to d-TGA. Cyanosis is usually caused by inadequate mixing of systemic and pulmonary circulation, and improved atrial or ductal mixing by emergent balloon atrial septostomy and prostaglandin E1 may be needed.

In DORV with doubly committed VSD, conal septum is deficient, and VSD is usually nonrestrictive. The prevalence is rare, and the hemodynamic is determined by out flow tract obstructions. In DORV with remote VSD or noncommitted VSD, the defects can be within muscular septum or AV canal septum. Because the distance of VSD and semilunar valves are far, surgical management is sometimes restricted.

Different anatomical arrangements have impacts on hemodynamic presentation, and influence the surgical planning (Lancour-Gayet, 2008). In addition to confirming diagnosis, preoperative TEE should provide information that help to determine a suitable surgical procedure. The size and relative position of VSD to great artery locations should be evaluated by preoperative TEE. Color Doppler gives information of outflow tract obstruction. The presence of pulmonary stenosis or aortic stenosis, either valvular or subvalvular, can be imaged in multiple views. The relative size of both ventricles, the presence of AV valve straddling, the pulmonary valve to tricuspid valve distance, and presence of other associated cardiac anomalies should all be evaluated by preoperative TEE (Figure 18).

In most cases, the goal of surgery is to complete biventricular repair and restore normal circulation. Surgeons will establish unobstructed LV to aorta continuity, establish adequate RV to PA continuity, and repair associated lesions. Some patients with DORV and subpulmonary VSD are repaired with arterial switch operation after baffling the LV to PA through VSD. Occasionally, in patients with unbalanced ventricle or other associated 
anomalies, two-ventricle repair is not feasible and operation toward single ventricle physiology is needed.

Postoperative complications generally fall into four groups: LV failure, RV failure, arrhythmia, and residual shunts. Because LV flow is baffled through VSD to great artery, obstruction occurs with poor configuration of the patch or insufficient enlarged VSD size. It is especially difficult in DORV with remote VSD. Aortic insufficiency may occur due to surgical damage. Residual RVOT obstruction can occur whether the repair acquired infundibulotomy, outflow tract patch, or some form of RV to PA conduit. Intracardiac baffle may compromise RVOT flow, especially in DORV with subpulmonary VSD, because the VSD is very close to pulmonary orifice and infundibular septal band. Tricuspid insufficiency may happen if chordae resection and reattachment is needed to accommodate baffle implantation. After arterial switch operation, neo-PA or branched PA obstruction should be carefully surveyed. Residual shunt may be caused by incomplete VSD repair, baffle detachment, and unrecognized multiple VSDs. It is prudent to carefully evaluate the repair by TEE before leaving operation room.

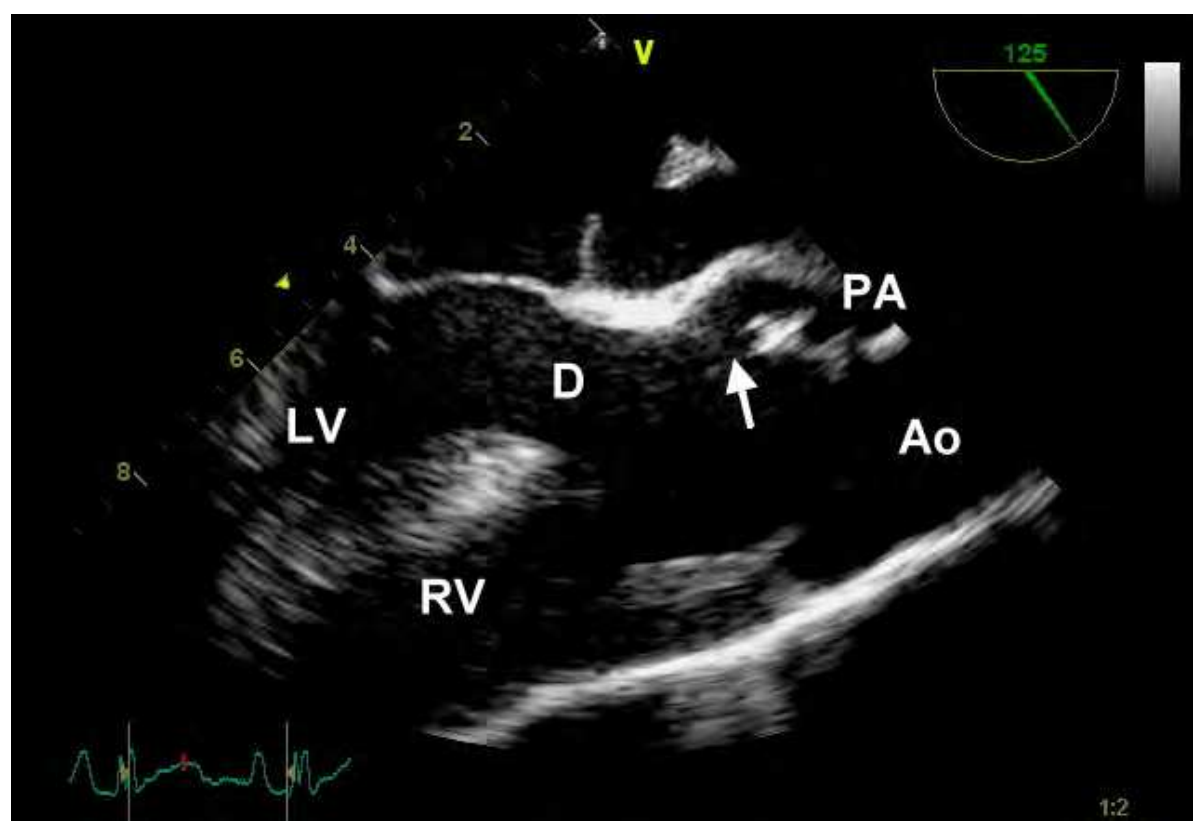

Fig. 18. Double-outlet right ventricle. The mid-esophageal long-axis view demonstrates both aorta (Ao) and pulmonary artery (PA) arises from right ventricle (RV) and the presence of pulmonary stenosis (arrow) and ventricular septal defect (D). LV, left ventricle; RV, right ventricle.

\subsection{Single ventricular physiology}

The functionally univentricular circulation, or single-ventricle physiology, is a heterogenous group of cardiac abnormalities. In most patients, there is hypoplasia of either the RV or LV 
which is unable to maintain a pulmonary or systemic circulation independently (Khairy et al., 2007). This anatomical category includes hypoplastic left heart syndrome, tricuspid atresia, and double-inlet LV (Figure 19). Two-ventricular repair may not be feasible in some complex congenital heart disease even with balanced ventricles, such as malpositioned or straddling AV valve, or DORV with a remote VSD, and single ventricle management strategy must be undertaken.

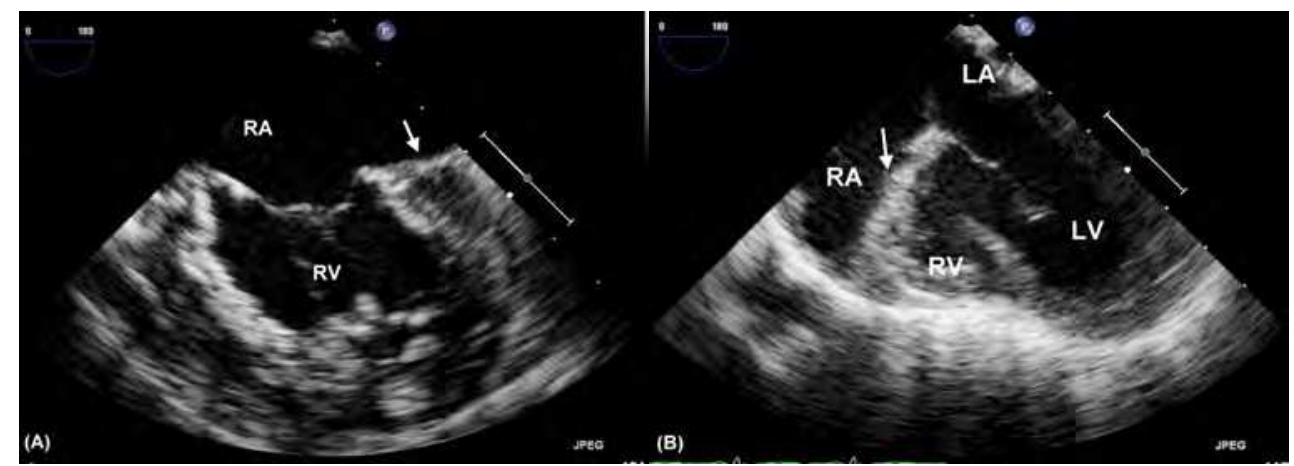

Fig. 19. Single ventricle physiology. (A) Hypoplastic left heart syndrome. The midesophageal short-axis view shows the mitral atresia (arrow) and hypoplasia of left ventricle (LV). (B) Tricuspid atresia. The mid-esophageal short-axis view demonstrates the tricuspid atresia (arrow) and hypoplasia of right ventricle (RV). RA, right atrium.

In single ventricle anatomy, the functional ventricle provides a common mixing chamber, and must pump both the systemic and pulmonary circulations, which easily lead to volume overload, cyanosis, or congestive heart failure. This pathophysiology encompasses a complex group of diseases. The presence of systemic and pulmonary outflow tract obstruction both contribute to the clinical manifestation.

Current surgical management of single ventricle is divided into 3 stages. Stage I operation technique is dependent on patients' status. Surgical palliation is to achieve following goals: unobstructive systemic blood flow, balanced and limited pulmonary blood flow, minimal AV valve regurgitation, nondistorted pulmonary arteries, and unrestricted return of blood to the ventricle. If pulmonary flow is unrestricted, pulmonary banding is done to minimize ventricular overload and avoid pulmonary hypertension. If systemic obstruction is noted, Norwood operation or Damus-Kaye-Stansel palliation is used. A systemic to pulmonary shunt, such as Blalock-Taussig (B-T) shunt is placed to provide pulmonary blood flow in patients with obstructed pulmonary circulation. In addition, AV valve repair and atrial septostomy may be needed according to patients' condition. The preoperative TEE exam includes the evaluation of AV and VA connections, AV valve morphology and function, degree of outflow tract obstruction, size and morphology of ventricles, and associated cardiac anomalies. The postoperative TEE exam should focus on the presence of systemic outflow tract obstruction, AV valve function, status of pulmonary blood flow and ventricular function.

Stage II operation mainly aims to connect SVC to PA and eliminate or restrict other sources for pulmonary blood flow. Bidirectional Glenn shunt and hemi-Fontan anastomosis are representatives. Bidirectional Glenn shunt is built from SVC to PA. After the operation, the 
driving force to pulmonary circulation is SVC pressure. Part of the left to right shunt is removed, and thus relieving the volume load from single ventricle. Perioperative TEE exam includes the evaluation of the anastomosis site, PA morphology, AV valve function, and ventricular function.

Current approach for stage III operation is Fontan operation or total cavopulmonary connection. Intracardiac lateral tunnel or extracardiac conduit may be used to create cavopulmonary connection. In this stage, pulmonary flow is dependent on systemic venous pressure, and all the pulmonary flow is effective. Fontan fenestration is sometimes provided to offer a source to systemic circulation that is not dependent on passing through pulmonary circulation. The perioperative TEE exam includes evaluation of the patency of cavopulmonary connection, AV valve function, size and flow of fenestration, and ventricular function (Figure 20).

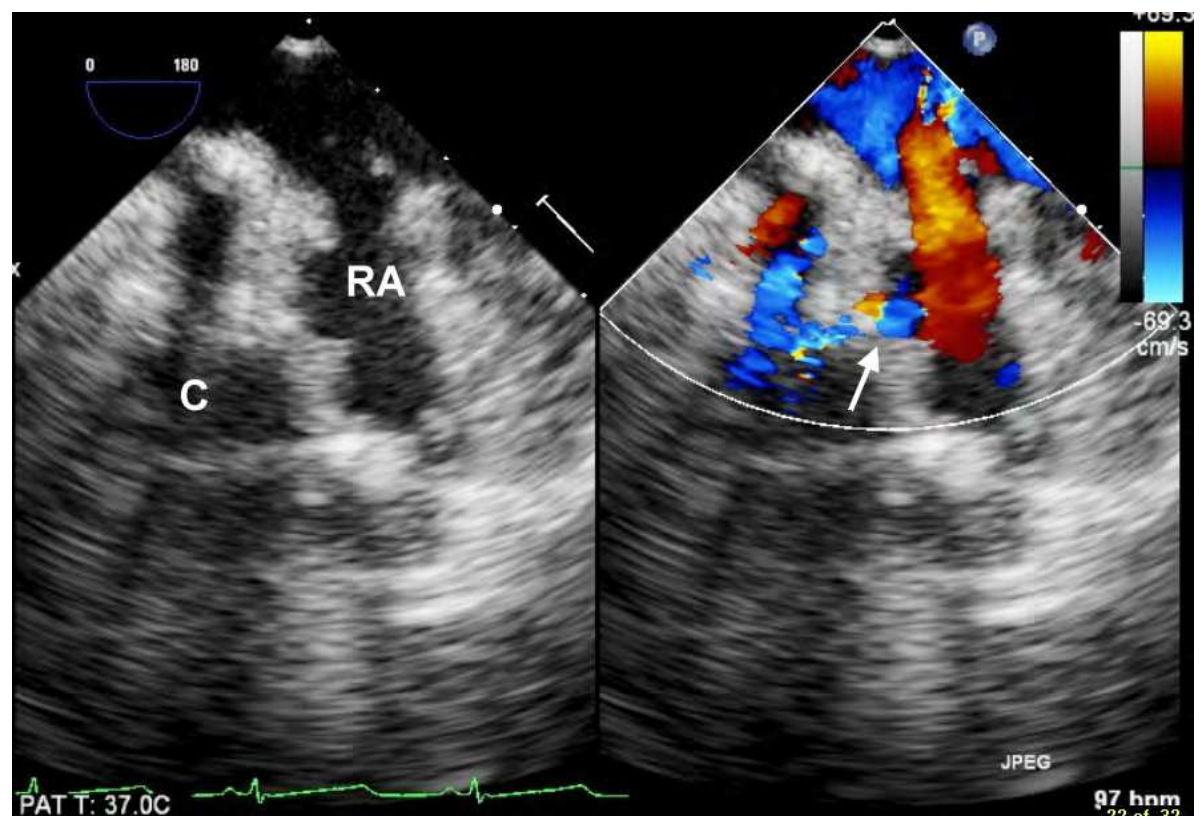

Fig. 20. There is a fenestration with shunt flow (arrow) between the extracardiac conduit (C) and right atrium (RA) after total cavopulmonary connection in a patient with tricuspid atresia.

\section{Conclusion}

Congenital heart disease is a complex disease entity of various severities. Intraoperative TEE offers valuable information about patients' anatomy and pathophysiology. In addition to diagnosis confirmation, TEE is a useful guide for surgical planning and anesthetic management. Intraoperative assessment by TEE images may be difficult due to complicated pathological presentations. A thorough understanding of anatomy, pathophysiology, and surgical procedure of congenital heart disease is required for interpretation of intraoperative TEE. 


\section{References}

Ayres, NA., Miller-Hance, W., Fyfe DA, et al.(2005) Indications and guidelines for performance of transesophageal echocardiography in the patient with pediatric acquired or congenital heart disease. A report from the task force of the pediatric council of the American society of echocardiography. Journal of American Society of Echocardiography, Vol.18, No.1, pp. 91-98.

Bettex, DA., Pretre, R., Jenni, R., et al.(2005) Cost-effectiveness of routine intraoperative transesophageal echocardiography in pediatric cardiac surgery: a 10-year experience. Anesthesia \& Analgesia, Vol.100, No.5, pp. 1271-1275.

Cohen, GA. \& Stevenson, JG. (2007) Intraoperative echocardioraphy for atrioventricular canal: decision-making for surgeons. Seminars in Thoracic and Cardiovascular Syrgery: Pediatric Cardiac Surgery Annual, Vol.10, No.1, pp. 47-50.

Huang, CH., Lu, CW., Lin, TY., et al. (2007) Complications of intraoperative transesophageal echocardiography in adult cardiac patients-experience of two institutions in Taiwan. Journal of the Formosan Medical Association, Vol.106, No.1, pp. 92-95.

Huang, HH., Lin, PL., Chao, IF., Chao, A. \& Huang, CH. (2009) Misdiagnosed right atrial tumor identified by intraoperative transesophageal echocardiography. Cardiology Journal, Vol.16, No.2, pp. 175-176.

Joffe, DC., Rivo, J., Oxorn, DC. (2008) Coronary sinus atrial septal defect. Anesthesia $\mathcal{E}$ Analgesia, Vol.107, No.4, pp. 1163-1165.

Kamra, K., Russell, I., Miller-Hance, WC. (2011) Role of transesophageal echocardiography in the management of pediatric patients with congenital heart disease. Paediatric Anaesthesia, Vol.21, No.5, pp. 479-493.

Khairy, P., Poirier, N., Mercier, LA. (2007) Univentricular heart. Circulation, Vol.115, No.6, pp. 800-812.

Lacour-Gayet, F. (2008) Intracardiac repair of double outlet right ventricle. Seminars in Thoracic and Cardiovascular Syrgery: Pediatric Cardiac Surgery Annual, Vol.11, No.1, pp. 39-43.

Oechslin, E., Buchholz, S., Jenni, R. (2000) Ebstein's anomaly in adults: Dopplerechocardiographic evaluation. The Thoracic E Cardiovascular Surgeon, Vol.48, No.4, pp. 209-213.

Penny, DJ. \& Vick, GW. (2011) Ventricular septal defect. Lancet, Vol.377, No.9771, pp. 1103-1112.

Randolph, GR., Hagler, DJ., Connolly, HM., et al.(2002) Intraoperative transesophageal echocardiography during surgery for congenital heart defects. Journal of Thoracic $\mathcal{E}$ Cardiovascular Surgery, Vol.124, No.6, pp. 1176-1182.

Rosenthal, E. (2005) Coarctation of aorta from fetus to adult: curable condition of life long disease process? Heart, Vol.91, No.11, pp. 1495-1502.

Schneider,DJ., \& Moore, JW. (2006) Patent ductus arteriosus. Circulation, Vol.114, No.17, pp. 1873-1882.

Shinebourne, EA., Babu-Narayan, SV., Carvalho, JS. (2006) Tetralogy of Fallot: from fetus to adult. Heart, Vol.92, No.9, pp. 1353-1359.

Skinner, J., Hornung, T., Rumball, E. (2008) Transposition of the great arteries: from fetus to adult. Heart, Vol.94, No.9, pp. 1227-1235.

Thys, DM., Abel, MD., Brooker, RF., et al.(2010) Practice guidelines for perioperative transesophageal echocardiography. An updated report by the American society of anesthesiologistsand the society of cardiovascular anesthesiologists task force on transesophageal echocardiography. Anesthesiology, Vol.112, No.5, pp. 1084-1096. 


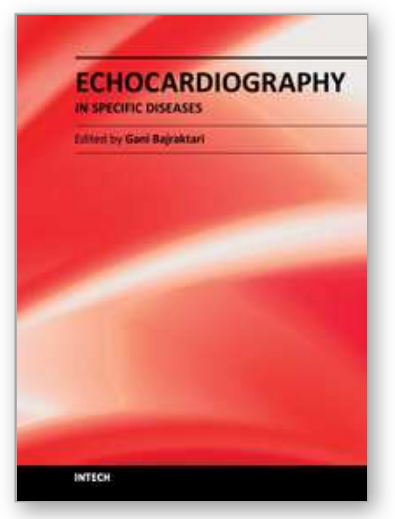

\author{
Echocardiography - In Specific Diseases \\ Edited by Prof. Gani Bajraktari
}

ISBN 978-953-307-977-6

Hard cover, 160 pages

Publisher InTech

Published online 18, January, 2012

Published in print edition January, 2012

The book "Echocardiography - In Specific Diseases" brings together contributions from well- known researchers from around the world, some of them specialized in imaging science in their clinical orientation, but also representatives from academic medical centers. Each chapter is structured and written to be accessible to those with a basic knowledge of echocardiography but also to be stimulating and informative to experts and researchers in the field of echocardiography. This book is primarily aimed at cardiology fellows during their basic echocardiography rotation, fellows of internal medicine, radiology and emergency medicine, but also experts in echocardiography. During the past few decades technological advancements in echocardiography have been developing rapidly, leading to improved echocardiographic imaging using new techniques. The authors of this book tried to explain the role of echocardiography in several special pathologies, which the readers may find in different chapters of the book.

\title{
How to reference
}

In order to correctly reference this scholarly work, feel free to copy and paste the following:

Yi-Chia Wang and Chi-Hsiang Huang (2012). Intraoperative Transesophageal Echocardiography for Congenital Heart Disease, Echocardiography - In Specific Diseases, Prof. Gani Bajraktari (Ed.), ISBN: 978953-307-977-6, InTech, Available from: http://www.intechopen.com/books/echocardiography-in-specificdiseases/intraoperative-transesophageal-echocardiography-for-congenital-heart-disease

\section{INTECH}

open science | open minds

\author{
InTech Europe \\ University Campus STeP Ri \\ Slavka Krautzeka 83/A \\ 51000 Rijeka, Croatia \\ Phone: +385 (51) 770447 \\ Fax: +385 (51) 686166 \\ www.intechopen.com
}

\author{
InTech China \\ Unit 405, Office Block, Hotel Equatorial Shanghai \\ No.65, Yan An Road (West), Shanghai, 200040, China \\ 中国上海市延安西路65号上海国际贵都大饭店办公楼 405 单元 \\ Phone: +86-21-62489820 \\ Fax: +86-21-62489821
}


(C) 2012 The Author(s). Licensee IntechOpen. This is an open access article distributed under the terms of the Creative Commons Attribution 3.0 License, which permits unrestricted use, distribution, and reproduction in any medium, provided the original work is properly cited. 